\title{
Pelatihan Penanganan Anak Berkebutuhan Khusus Bagi Guru Sekolah Dasar Rujukan Inklusi
}

\author{
Setyo Eko Atmojo ${ }^{1}$ \\ Universitas PGRI Yogyakarta, setyoekoatmojo@yahoo.co.id \\ Beny Dwi Lukitoaji ${ }^{2}$ \\ Universitas PGRI Yogyakarta, beny@upy.ac.id \\ Faiz Noormiyanto ${ }^{3}$ \\ Universitas PGRI Yogyakarta, faiz@upy.ac.id
}

\begin{abstract}
Abstrak
Kegiatan pelatihan ini bertujuan untuk membekali guru dalam menangani anak berkebutuhan khusus. Pelatihan ini diberikan pada guru kelas dengan siswa berkebutuhan khusus yang sangat memerlukan perhatian dan perlakukan yang khusus. Pembelajaran dan perlakuan bagi kelas yang memiliki anak berkebutuhan khusus berbeda dengan kelas biasa sehingga memerlukan guru yang mampu untuk menguasai kelas, siswa, pembelajaran dan penangan yang bersifat khusus bagi anak inklusif. Metode yang digunakan dalam pelatihan ini terdiri atas metode ceramah atau penyuluhan, praktik, dan simulasi. Pelatihan ini terdiri atas pemberian informasi, praktik penanganan dan pembelajaran di kelas inklusif yang didalamnya terdapat anak berkebutuhan khusus. Hasil pelatihan menunjukkan adanya peningkatan pengetahuan guru tentang penanganan bagi anak dengan kebutuhan khusus. Hal tersebut dapat dilihat pada skor post test guru setelah mengikuti pelatihan dimana $>75 \%$ guru telah memiliki pengetahuan yang baik tentang penanganan anak berkebutuhan khusus, selain itu berdasarkan hasil observasi pelaksanaan praktik pembelajaran diketahui bahwa $>70 \%$ guru telah mampu melaksanakan kegiatan pembelajaran dengan baik pada kelas inklusif.
\end{abstract}

Kata Kunci : Penanganan, Anak Berkebutuhan Khusus, Sekolah Rujukan Inklusif

\begin{abstract}
This training activity aims to equip teachers in dealing with children with special needs. This training is given to classroom teachers with students with special needs who really need special attention and treatment. Learning and treatment for classes that have children with special needs is different from ordinary classes so it requires teachers who are able to master classes, students, learning and handlers that are specific to inclusive children. The method used in this training consists of lecture or counseling, practice, and simulation methods. This training consists of providing information, handling practices and learning in inclusive classes in which there are children with special needs. The training results show an increase in teacher knowledge about handling for children with special needs. This can be seen in the post-test scores of teachers after participating in training where $>75 \%$ of teachers have good knowledge about handling children with special needs, besides that based on observations of
\end{abstract}


the implementation of learning practices it is known that $>70 \%$ of teachers have been able to carry out learning activities well in inclusive class.

Keywords: Handling, Children with Special Needs, Inclusive Reference Schools

\section{Pendahuluan}

Pemerintah Kabupaten Bantul melalui Dinas Pendidikan dan Kebudayaan Bantul (Dindikbud) telah menunjuk beberapa sekolah sebagai sekolah rujukan inklusif baik tingkat SD, SMP maupun SMA. Hal ini sejalan dengan mandat Kementerian Pendidikan dan Kebudayaan Republik Indonesia dalam UU No. 70 tahun 2009 dan Pergub No. 74 tahun 2014, yang terkait dengan pedoman untuk pendidikan inklusif di D.I Yogyakarta. Pembentukan sekolah rujukan inklusif dilaksanakan memenuhi mandat UU 70 tahun 2009 dan mendukung program education for all yang merupakan salah satu program dari Kementerian Pendidikan (Kemendikbud). Dengan demikian, sekolah inklusif di Bantul akan dapat dikembangkan, sehingga memungkinkan anak-anak dengan kebutuhan khusus untuk menerima pendidikan di sekolah umum berkualitas tinggi tetapi tidak termasuk dalam sekolah pendidikan khusus.

Penerapan program ini sangat disambut baik oleh seluruh masyarakat khususnya bagi orang tua yang memiliki anak berkebutuhan khusus. Bagi sekolah program ini memerlukan bekal khusus untuk melaksanakannya, dimana selama ini guru hanya menghadapi anak normal dalam satu kelas akan berubah karena adanya anak berkebutuhan khusus yang ikut masuk dan belajar di dalamnya. Pembelajaran di kelas inklusif tersebut tentunya akan membutuhkan penanganan yang berbeda dari sebelumnya (Hartadi et al., 2019); (Muchtar, 2018). Untuk membekali guru agar memiliki kemampuan dalam melaksanakan pembelajaran di kelas tersebut diperlukan suatu kegiatan yang membuat guru memiliki bekal pengetahuan dan keterampilan menangani anak berkebutuhan khusus.

Mitra dari kegiatan pengabdian ini adalah SD Brajan yang terletak di desa Tamantirto Kecamatan Kasihan Kabupaten Bantul. Berdasarkan hasil observasi dan wawancara terhadap 12 orang guru dan kepala sekolah diketahui 83,33\% guru belum memiliki pengetahuan tentang pelaksanaan pembelajaran dan penanganan anak berkebutuhan khsusus. Berdasarkan hal tersebut maka diperlukan pelatihan tentang penanganan anak berkebutuahan khusus di sekolah tersebut. Solusi yang ditawarkan melalui kegiatan ini yaitu pelatihan penanganan anak berkebutuhan khusus di Sekolah Dasar Rujukan Inklusif. Kegiatan pelatihan ini terdiri dari kegiatan penyuluhan penanganan anak berkebutuhan khusus, pengembangan perangkat pembelajaran untuk Sekolah Dasar Inklusif dan pengembangan media pembelajaran untuk siswa berkebutuhan khusus.

Berdasarkan hasil observasi dan wawancara terhadap guru di SD Brajan Kasihan Bantul diketahui bahwa sebagaian besar guru belum memiliki kemampuan dalam menangani anak berkebutuhan khusus dan pelaksanaan pembelajaran di kelas inklusif. Melalui kegiatan pengabdian ini akan dilaksanakan suatu pelatihan bagi guru di SD Brajan Kasihan Bantul dengan tujuan membekali guru agar memahami prinsip penyelenggaraan pendidikan inklusif, memahami dan mampu membedakan 
jenis-jenis gangguan perkembangan dan karakteristik kondisi kekhususan yang disandang anak didik, mampu membuat program pembelajaran yang efektif bagi anak dengan kondisi Autisma, Asperger, Gangguan Emosional dan Perilaku, Gangguan Konsentrasi \& Perilaku Hiperaktivitas, Gangguan Belajar dan Lamban Belajar, serta Cerdas Berbakat Istimewa di sekolah, memiliki kompetensi memadai dalam menyusun, mengembangkan, dan menerapkan program pembelajaran yang sesuai dengan kondisi kekhususan anak didik di sekolah, mampu mengarahkan dan menggerakkan penanganan dari kondisi kekhususan anak didik sehingga anak bisa keluar dari hambatan yang ada dan mampu mengoptimalkan potensinya.

\section{Metode}

Kegiatan pelatihan ini menggunakan beberapa metode antara lain ceramah atau penyuluhan, praktik, dan simulasi (Listyaningsih, L., Hartati, S. J., \& Irmayanti, D, n.d.). Penjelasan masing masing kegiatan tersebut adalah sebagai berikut

1. Metode ceramah/penyuluhan

Kegiatan ceramah atau penyuluhan ini dimaksudkan untuk memberikan pengetahuan tentang penanganan anak berkebutuhan khusus. Materi yang disampaikan antara lain tentang Pendidikan Inklusif, Keberagaman Kondisi Anak, Perkembangan Anak dan Teori Belajar, dan Perkembangan dan Gangguan Bicara-Bahasa.

2. Metode Praktik

Metode praktik ini adalah mempraktikan dari pengetahuan yang telah dilakukan dalam situasi kelas. Kegiatan praktik ini meliputi Asesmen dan Konseling Dasar anak dengan kondisi Autisma, Asperger, Gangguan Emosional dan Perilaku, Gangguan Konsentrasi \& Perilaku Hiperaktivitas, Gangguan Belajar dan Lamban Belajar, serta Cerdas Berbakat Istimewa.

3. Metode Pelatihan, Praktik dan Simulasi

Metode pelatihan ini adalah berisi kegiatan pelatihan pengembangan perangkat dan media untuk sekolah inklusif. Setelah peserta mengetahui langkah pembelajaran bagi kelas inklusif dan media yang diperlukan peserta selanjutnya membuat dan mengembangkannya. Setelah berhasil mengembangkannya selanjutnya Perangkat pembelajaran dan media yang dihasilkan kemudian di simulasikan dalam kelas inklusif.

\section{Hasil dan Pembahasan}

Kegiatan pengabdian ini dilaksanakan sebanyak lima kali pertemuan pada bulan April hingga Mei 2020. Dimana setiap sesi memiliki jeda waktu selama satu minggu. Keberhasilan program ini dapat dilihat dari peningkatan pengetahuan dan keterampilan guru dalam menangani anak berkebutuhan khusus, mengembangkan dan melaksanakan pembelajaran untuk sekolah inklusif dengan rancangan pembelajaran yang sesuai dan menggunakan media pembelajaran yang diperlukan bagi anak berkebutuhan khusus. Kegiatan pelatihan ini dilakukan sebanyak lima kali sesuai dengan Tabel 1. 
Tabel 1. Jadwal Kegiatan Pelatihan

\begin{tabular}{|c|c|c|}
\hline No & Kegiatan & Waktu \\
\hline 1 & Persiapan Kegiatan & 6-8 April 2020 \\
\hline 2 & Pelaksanaan Kegiatan 1 & 11 April 2020 \\
\hline & $\begin{array}{l}\text { Penyuluhan tentang Pendidikan Inklusif, Keberagaman Kondisi Anak, } \\
\text { Perkembangan Anak dan Teori Belajar, dan Perkembangan dan } \\
\text { Gangguan Bicara-Bahasa. }\end{array}$ & \\
\hline 3 & $\begin{array}{l}\text { Pelaksanaan Kegiatan } 2 \\
\text { Praktik melakukan Asesmen dan Konseling Dasar anak dengan kondisi } \\
\text { Autisma, Asperger, Gangguan Emosional dan Perilaku, Gangguan } \\
\text { Konsentrasi \& Perilaku Hiperaktivitas, Gangguan Belajar dan Lamban } \\
\text { Belajar, serta Cerdas Berbakat Istimewa. }\end{array}$ & 18 April 2020 \\
\hline 4 & $\begin{array}{l}\text { Pelaksanaan Kegiatan } 3 \\
\text { Pelatihan pengembangan perangkat dan media untuk sekolah inklusif. }\end{array}$ & 25 April 2020 \\
\hline 5 & $\begin{array}{l}\text { Pelaksanaan Kegiatan } 4 \\
\text { Praktik penyusunan perangkat dan media untuk sekolah inklusif. }\end{array}$ & 2 Mei 2020 \\
\hline 6 & $\begin{array}{l}\text { Pelaksanaan Kegiatan } 5 \\
\text { Simulasi pembelajaran menggunakan perangkat dan media untuk } \\
\text { sekolah inklusif yang telah dikembangkan }\end{array}$ & 9 Mei 2020 \\
\hline
\end{tabular}

Kegiatan penyuluhan dan praktik praktik asesment dalam kegiatan ini dapat dilihat pada Gambar 1 dan Gambar 2.

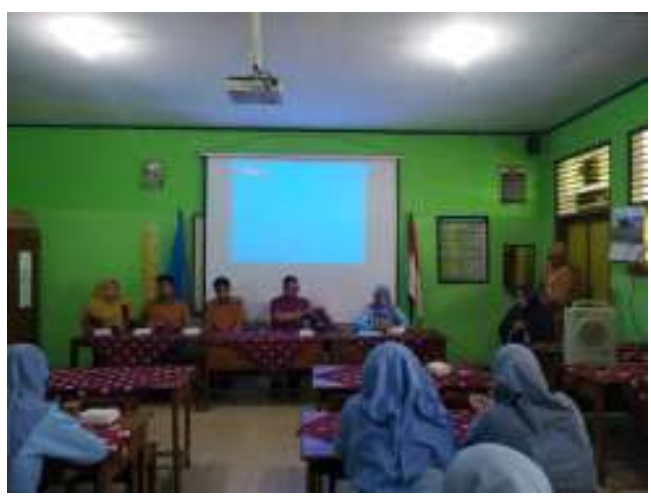

Gambar 1. Penyuluhan

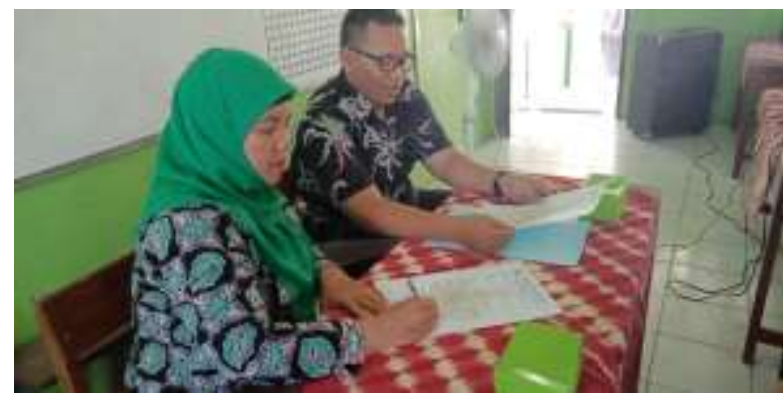

Gambar 2. Praktik Asesment

Seluruh kegiatan pengabdian ini dilaksanakan dengan menerapakan protokol kesehatan Covid-19 karena kegiatan ini dilaksanakan di tengah pandemi Covid 19. Gambar 1 merupakan kegiatan penyuluhan tentang tentang Pendidikan Inklusif, Keberagaman Kondisi Anak, Perkembangan Anak dan Teori Belajar, dan Perkembangan dan Gangguan Bicara - Bahasa. Sedangkan Gmbar 2 merupakan Praktik melakukan Asesmen dan Konseling Dasar anak dengan kondisi Autisma, Asperger, Gangguan Emosional dan Perilaku, Gangguan Konsentrasi \& Perilaku Hiperaktivitas, Gangguan Belajar dan Lamban Belajar, serta Cerdas Berbakat Istimewa. Kegiatan ini dilaksanakan oleh sluruh tim pengabdi dengan penanggung jawab utama yaitu bapak Faiz Noormiyanto yang memiliki basic keilmuan bidang anak berkebutuhan khusus.

Kegiatan berikutnya yaitu pengembangan perangkat dan media yang dapat dilihat pada Gambar 3 dan Gambar 4. Kegiatan pengembangan perangkat dan media di 
sekolah dasar ini dilaksanakan oleh seluruh tim dengan penenggung jawab bapak Setyo Eko Atmojo dan bapak Beny Dwi Lukitoaji yang merupakan dosen program studi PGSD sehingga sesuai dengan kebutuhan peserta yang merupakan guru guru sekolah dasar.

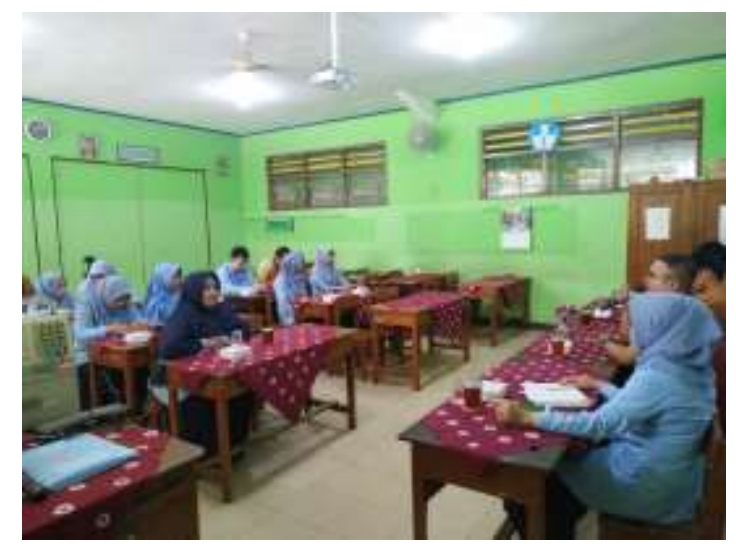

Gambar 3 Pelatihan Perangkat Pembelajaran

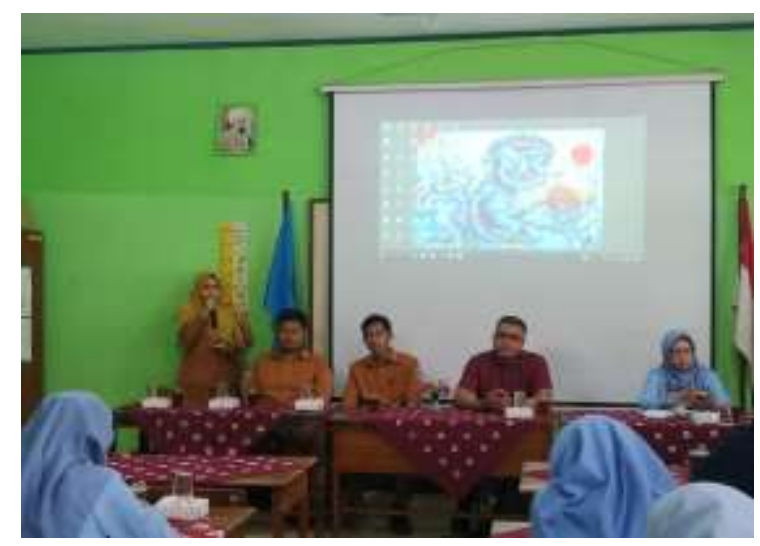

Gambar 4. Praktik Pengambangan Media

Kegiatan berikutnya yaitu simulasi penerapan perangkat dan media pembelajaran hasil pelatihan dalam kelas. Kegiatan seimulasi ini dilaksanakan secara micro dengan mematuhi protokol Covid -19. Kegiatan ini dilaksanakan dengan waktu 15 menit dan manghadirkan setengah dari jumlah siswa keseluruhan dalam satu kelas. Kegiatan simulasi micro ini sebelumnya telah mendapat ijin dari kepala desa, ketua RT dan gugus tugas Covid 19 di desa setempat serta orang tua siswa. Kegiatan simulasi secara micro dapat dilihat pada Gambar 5 dan Gambar 6.

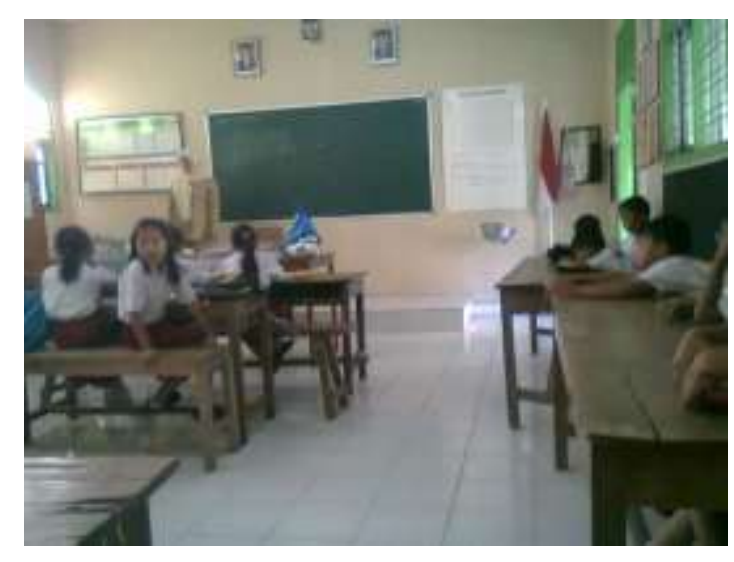

Gambar 5. Praktik Simulasi Micro

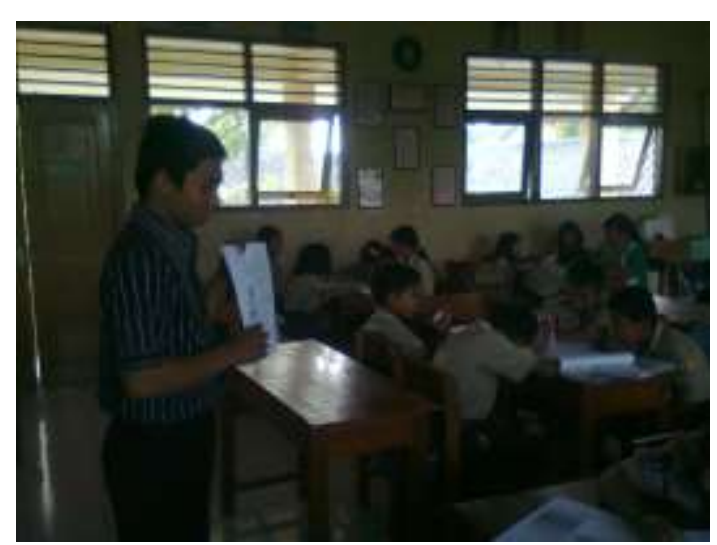

Gambar 6. Praktik Simulasi Micro

Setelah melaksanakan kegiatan pelatihan selama lima kali dalam waktu kurang lebih dua bulan diperoleh hasil pengetahuan guru tentang penanganan anak berkebutuhan khusus. Bersadarkan hasil post test yang dilakukan setelah kegiatan pelatihan diketahui bahwa telah terjadi peningkatan pengetahuan tentang penanganan anak berkebutuhan khusus. Hasil pre test dan post test pengetahuan tentang penanganan anak berkebutuhan khusus ini dapat dilihat pada Tabel 2. 
Tabel 2. Hasil Test Pengetahuan Tentang Penanganan Anak Berkebutuhan Khsusus

\begin{tabular}{clccc}
\hline No & \multicolumn{1}{c}{ Nama } & Skor Pre Test & Skor Post Test & $\begin{array}{c}\text { Persentase } \\
\text { Peningkatan }\end{array}$ \\
\hline 1 & Muginah, M.Pd. & 52 & 83 & 82,48 \\
2 & Ita Eliyana, S.Pd. & 50 & 86 & 85,5 \\
3 & Syarifatun, S.Pd. & 56 & 89 & 88,44 \\
4 & Warsiyanti, S.Pd. & 57 & 88 & 87,43 \\
5 & Esdi Waluyo, S.Pd. & 55 & 85 & 84,45 \\
6 & Suti Harni, S.Pd. & 54 & 87 & 86,46 \\
7 & Suratmi, S.Pd. & 60 & 81 & 80,4 \\
8 & Sumarsih, S.Pd. & 61 & 79 & 78,39 \\
9 & Sarjiman, S.Pd. & 53 & 89 & 88,47 \\
10 & Salimah, S.Pd. & 52 & 85 & 84,48 \\
11 & Riyantini, S.Pd. & 51 & 86 & 85,49 \\
12 & Eny Maryatini, S.Pd. & 49 & 83 & 82,51 \\
\hline & & & & 84,54 \\
\hline
\end{tabular}

Berdasarkan Tabel 2 diketahui bahwa telah terjadi peningkatan pengetahuan guru tentang penanganan anak berkebutuhan khusus sebelum dan sesudah pelatihan. Peningkatan yang terjadi dari masing-masing guru lebih dari 70\%. Berdasarkan Tabel 2 juga diketahui bahwa rata rata peningkatan pengetahuan tentang penanganan anak berkebutuhan khusus sebesar $84,54 \%$. Peningkatan pengetahuan ini terjadi karena adanya pelatihan tentang penanganan anak berkebutuhan khusus. Pelatihan yang dilaksanakan menggunakan Metode ceramah/penyuluhan, praktik, dan simulasi. Metode caramah atau penyuluhan ini dilaksanakan pada awal kegiatan untuk memberikan bekal pengetahuan tentang penanganan anak berkebutuhan khusus (Sundqvist et al., 2019); (Hsiao \& Sorensen Petersen, 2019); (Poerwanti et al., 2015). Penyuluhan ini berisi materi tentang kemampuan dalam membantu pembelajaran peserta didik yang memiliki kondisi Autism Spectrum Disorder (ASD), Attention Deficit Hyperactivity Disorder (ADHD), Kesulitan belajar spesifik (Specific Learning Disabilities) dan lamban belajar (Slow Learner), gangguan emosi perilaku (Emotional Behavior Disorder), dan Cerdas Berbakat Istimewa (Gifted). Metode ceramah dan penyuluhan ini mampu memberikan perubahan pada pengetahuan guru dalam menangani anak berkebutuhan khusus, hal tersebut sesuai dengan (Wonosobo, n.d.) yang mengungkapkan bahwa ceramah dan penyuluhan ini mampu meningkatkan pengetahuan guru PAUD di Kabupaten Wonosobo.

Selain pengetahuan penanganan anak berkebutuhan khusus kegiatan ini juga bertujuan untuk mengetahui kemampuan guru dalam melaksanakan kegiatan pembelajaran di kelas yang di dalamnya terdapat siswa inklusi. Untuk mengetahui keterampilan guru dalam mengelola pembelajaran maka dilakukan observasi selama guru melaksanakan praktik penyusunan perangkat pembelajaran (RPP) dan pelaksanaannnya di dalam kelas atau simulasi. Hasil observasi dari praktik penyusunan perangkat pembelajaran dan simulasi ini dapat dilihat pada Tabel 3. 
Tabel 3. Hasil Observasi Praktik dan Simulasi Pembelajaran

\begin{tabular}{|c|c|c|c|}
\hline No & Nama & $\begin{array}{c}\text { Skor Praktik } \\
\text { Penyusunan RPP }\end{array}$ & Skor Simulasi RPP \\
\hline 1 & Muginah, M.Pd. & 72 & 77 \\
\hline 2 & Ita Eliyana, S.Pd. & 74 & 72 \\
\hline 3 & Syarifatun, S.Pd. & 77 & 73 \\
\hline 4 & Warsiyanti, S.Pd. & 78 & 74 \\
\hline 5 & Esdi Waluyo, S.Pd. & 72 & 78 \\
\hline 6 & Suti Harni, S.Pd. & 73 & 73 \\
\hline 7 & Suratmi, S.Pd. & 78 & 75 \\
\hline 8 & Sumarsih, S.Pd. & 80 & 78 \\
\hline 9 & Sarjiman, S.Pd. & 83 & 76 \\
\hline 10 & Salimah, S.Pd. & 76 & 77 \\
\hline 11 & Riyantini, S.Pd. & 78 & 72 \\
\hline 12 & Eny Maryatini, S.Pd. & 82 & 80 \\
\hline & Rata Rata Skor & 76,92 & 75,42 \\
\hline
\end{tabular}

Berdasarkan Tabel 3 diketahui bahwa setelah pelatihan ini diketahui bahwa rata rata skor Praktik Penyusunan RPP sebesar 76,92 yang termasuk apda kategori baik. Hal ini menunjukkan bahwa kegiatan pelatihan ini memberikan bekal pada guru dalam menyusun perangkat pembelajaran untuk sekolah rujukan inklusi. Kegiatan praktik ini terbukti mampu memberikan peningkatan pada kemampuan menyusun perangkat pembelajaran, hal tersebut sejalan dengan pendapat (Rohita \& Fitria, 2019) yang mengungkapkan bahwa kegiatan praktik mampu meningkatkan keterampilan guru menyusun RPP Kurikulum 2013.

Kegiatan praktik ini memiliki kelebihan yaitu menambah keterampilan, pengetahuan, gagasan-gagasan seputar kegiatan pembelajaran untuk sekolah rujukan inklusi sehingga mampu menjadikan guru yang lebih profesional dan handal. Selain itu kegiatan praktek ini mampu membentuk pola pikir guru agar terkonstruktif baik serta memberikan pengalaman dalam penyusunan rencana pembelajaran di kelas rujukan inklusi. Pada kegiatan pelatihan ini RPP disusun dengan tujuan mewadahi siswa umum (reguler) dan khusus dalam satu kelas. RPP inklusi ini disusun dengan modifikasi yakni terdapat indikator yang disesuaikan bagi siswa umum dan ABK (Sholawati, 2019); (Utaminingsih et al., 2018). Perencanaan pembelajaran disusun berdasarkan hasil asesmen siswa. Asesmen adalah suatu proses pengumpulan informasi tentang perkembangan peserta didik dengan menggunakan alat dan teknik yang sesuai untuk membuat keputusan pendidikan yang berkenaan dengan penempatan dan program yang sesuai bagi peserta didik tersebut (Wahyuni, 2019); (Aisah, 2019).

Sebagai salah satu contoh RPP yang dihasilkan dari pelatihan ini yaitu RPP Kelas 1 semester dua dengan Tema 7. Benda, Hewan dan Tanaman Di Sekitarku, Sub Tema 2. Hewan di sekitarku dengan Alokasi Waktu 1 Pertemuan (6 X 30 Menit). Selain RPP hasil pelatihan ini juga menghasilkan media dan bahan ajar untuk kelas inklusi, sehingga selain RPP hasil pelatihan ini juga menghasilkan bahan ajar dan media untuk siswa inklusi. Pembelajaran akan efektif apabila terdapat kesesuaian antara 
RPP dengan media dan bahan ajar yang digunakan (Sholeh \& Sutanta, 2019). Selanjutnya RPP dan media serta bahan ajar yang telah disusun ini disimulasikan dalam kelas inklusi dan dilakukan observasi untuk mengetahui sejauhmana dapat diterapkan dalam kelas. Hasil observasi kegiatan praktik penyusunan RPP dan simulasinya dapat dilihat pada Tabel 3.

Berdasarkan Tabel 3 juga dapat diketahui bahwa kemampuan guru dalam mengelola pembelajaran mengalami perubahan. Hal tersebut terlihat pada rata-rata skor Simulasi RPP sebesar 75,42 yang berada pada kategori baik. Hasil simulasi ini menegaskan keberhasilan kegiatan pelatihan ini, dimana setelah mengikuti pelatihan ini guru mampu memperolah skor pelaksanaan pembelajaran yang baik. Kegiatan simulasi ini memiliki beberapa kelebihan diantaranya adalah metode simulasi ini dapat meningkatkan pengetahuan, sikap, dan keterampilan guru dalam melakukan pembelajaran di kelas inklusif. Selain itu, pelatihan ini juga memberikan pengalaman secara langsung tentang hal hal yang diperlukan oleh guru dalam menghadapi permasalahan yang berhubungan dengan siswa ABK.

Setelah mengikuti pelatihan ini guru dapat menyediakan kondisi kelas yang hangat, ramah, menerima keanekaragaman dan menghargai perbedaan, mengelola kelas yang heterogen dengan menerapkan kurikulum dan pembelajaran yang bersifat individual, menerapkan pembelajaran yang interaktif, melakukan kolaborasi dengan profesi atau sumberdaya lain dalam perencanaan pelaksanaan dan evaluasi dan melibatkan orang tua secara bermakna dalam proses pendidikan. Dengan mengikuti pelatihan ini dan memiliki pengetahuan tentang penanganan anak berkebutuhan khusus, penyusunan RPP dan mensimulasikannya maka guru telah siap untuk melaksanakan kegiatan pembelajaran di kelas inklusi dengan memperhatikan tata cara penanganan anak berkebutuhan khusus.

\section{Simpulan dan Rekomendasi}

Simpulan dari kegiatan pelatihan ini adalah meningkatnya kemampuan guru dalam menangani anak berkebutuhan khusus di sekolah dasar rujukan inklusi. Hal tersebut dapat dilihat dari hasil post test, observasi praktik dan simulasi pembelajaran di kelas inklusi. Rekomendasi yang dapat dberikan berdasakan hasil ini yaitu kegiatan pelatihan ini dapat dilaksanakan dalam ruang lingkup yang lebih luas manfaat pelatihan ini dapat dirasakan oleh masyarakat luas.

\section{Acknowledgements}

Terimakasih kapada Lembaga Penelitian dan Pengabdian Masyarakat (LPPM) Universitas PGRI Yogyakarta yang telah mendanai penelitian ini melalui anggaran PPM tahun 2019/2020 dengan nomor kontrak: 319/BAP-LPPM/IV/2020.

\section{Daftar Pustaka}

Aisah. (2019). Upaya Meningkatkan Minat Belajar Anak Berkebutuhan Khusus Pada Kelas Ii Sdn Unggulan Melalui Metode Full Inclusion. Pedagogi: Jurnal Penelitian Pendidikan, 6, 1-9.

Hartadi, D. R., Dewantoro, D. A., \& Junaidi, A. R. (2019). Kesiapan Sekolah dalam Melaksanakan Pendidikan Inklusif untuk Anak Berkebutuhan Khusus di 
Sekolah Dasar. Jurnal Ortopedagogia, 5(2), 90-95.

Hsiao, Y. J., \& Sorensen Petersen, S. (2019). Evidence-Based Practices Provided in Teacher Education and In-Service Training Programs for Special Education Teachers of Students With Autism Spectrum Disorders. Teacher Education and Special Education, 42(3), 193-208. https:/ / doi.org/10.1177/0888406418758464

Listyaningsih, L., Hartati, S. J., \& Irmayanti, D, 2019. (n.d.). Prosiding SEMNAS ABDIMAS 2019.

Muchtar, A. D. (2018). IMPLEMENTASI KURIKULUM PAI 2013 PADA ANAK BERKEBUTUHAN KHUSUS DI SMPLB BHAKTI KENCANA YOGYAKARTA. Edumaspul - Jurnal Pendidikan. https:// doi.org/10.33487/edumaspul.v2i1.16

Poerwanti, E., Soenaryo, S. F., \& Restian, A. (2015). Peningkatan Pengetahuan Dan Keterampilan Guru SD Muhammadiyah 4 Batu Dalam Mengelola Pembelajaran ABK melalui Lesson Study. JINoP (Jurnal Inovasi Pembelajaran), 1(1), 12. https://doi.org/10.22219/jinop.v1i1.2444

Rohita, \& Fitria, N. (2019). Pelatihan Penyusunan Rencana Pelaksanaan Pembelaja-. Jurnal Pemberdayaan Masyarakat Universitas Al Azhar Indonesia, 01(01), 22-32.

Sholawati, S. A. (2019). MANAJEMEN PEMBELAJARAN PENDIDIKAN INKLUSI PADA ANAK BERKEBUTUHAN KHUSUS DI SDN KALIRUNGKUT-1 SURABAYA. Abdau: Jurnal Pendidikan Madrasah Ibtidaiyah. https://doi.org/10.36768/abdau.v2i1.24

Sholeh, M., \& Sutanta, E. (2019). Pendampingan Pengembangan Bahan Ajar dengan Videoscribe pada Guru Smk Tembarak Temanggung. Jurnal Pengabdian Kepada Masyarakat, 2(Februari), 1-9. http:/ / ejournal.bsi.ac.id/ejurnal/index.php/abdimas

Sundqvist, C., Björk-Åman, C., \& Ström, K. (2019). The three-tiered support system and the special education teachers' role in Swedish-speaking schools in Finland. European Journal of Special Needs Education, 34(5), 601-616. https://doi.org/10.1080/08856257.2019.1572094

Utaminingsih, R., Rahayu, A., \& Andini, D. W. (2018). Pengembangan RPP IPA sekolah dasar berbasis problem-based learning untuk siswa learning disabilities Development of primary school natural science lesson plan based on problembased learning for learning disabilities students. Jurnal Inovasi Pendidikan IPA, $4(2), 191-202$.

Wahyuni, S. I. (2019). Manajemen Kurikulum Pendidikan Agama Islam bagi Anak Berkebutuhan Khusus di SLB Al Azhar Bukittinggi. MANAGERIA: Jurnal Manajemen Pendidikan Islam, 4(2), 219-240. https:// doi.org/10.14421/manageria.2019.42-03

Wonosobo, D. I. K. (n.d.). Guru Paud Dalam Melakukan Sdidtk. Jurnal PPKM, Vol. 6, No. 1, $31-36,6(1), 31-36$. 